\title{
Analysis of energy requirement for hemp fibre decortication using a hammer mill
}

\author{
J. Xu1 ${ }^{1}$, Y. Chen ${ }^{1 *}$, C. Laguë2, H. Landry ${ }^{3}$ and Q. Peng ${ }^{4}$ \\ ${ }^{I}$ Department of Biosystems Engineering, University of Manitoba, Winnipeg, Manitoba, R3T 5V6 Canada; \\ ${ }^{2}$ Faculty of Engineering, University of Ottawa, Ottawa, Ontario, K1N 6N5 Canada; \\ ${ }^{3}$ Prairie Agricultural Machinery Institute (PAMI), Humboldt, Saskatchewan, SOK 2 AO Canada; \\ ${ }^{4}$ Department of Mechanical Engineering, University of Manitoba, Winnipeg, Manitoba, R3T 5V6 Canada. \\ *Email:ying_chen@umanitoba.ca
}

Xu, J., Y. Chen, C. Laguë, H. Landry and Q. Peng. 2012. Analysis of energy requirement for hemp fibre decortication using a hammer mill. Canadian Biosystems Engineering/Le génie des biosystèmes au Canada 54: 2.1-2.8. Hemp fibre decortication is an important procedure in hemp fibre processing. The cost of energy during decortication has a direct impact on the commercial value of hemp fibres for industrial products. This study investigated the specific energy requirement for hemp decortication using a hammer mill and the length size distribution of output fibre. Three screen opening sizes $(19.28 \mathrm{~mm}, 25.74 \mathrm{~mm}$, and no-screen scenario) and three feeding masses (200 g, $125 \mathrm{~g}$, and $75 \mathrm{~g}$ ) were used in hammer mill decortication tests. Test results showed that the $200 \mathrm{~g}$ feeding mass and the small screen opening size required the highest specific energy $(73.84 \mathrm{~J} / \mathrm{g})$. Screen opening size affected the fibre length distribution. For all three feeding mass scenarios, more short fibres were produced when a smaller screen opening was used. Based on the results of analysis using existing Kick's, Rittinger's, and Bond's laws, a linear model was developed to fit the test data in regard to relating specific energy with initial and final fibre lengths. The model performed well for specific energy estimations, especially for the case under 200 g feeding mass. Keywords: hemp, decortication, fibre, energy, hammer mill.

La décortication de la fibre de chanvre est une opération important dans la transformation de la fibre de chanvre. Le coût énergétique durant la décortication a un impact direct sur la valeur commerciale des fibres de chanvre pour les produits industriels. Cette étude évalue les demandes énergétiques spécifiques à la décortication du chanvre par un broyeur à marteau et la distribution de la longueur des fibres obtenues. Trois dimensions d'ouverture de tamis $(19,28 \mathrm{~mm}, 25,74 \mathrm{~mm}$ et pas de tamis) et trois masses d'alimentation $(200 \mathrm{~g}$. $125 \mathrm{~g}$ et $75 \mathrm{~g})$ ont été utilisés pour les essais de décortication dans le broyeur à marteau. Les résultats des essais ont démontré que l'alimentation de $200 \mathrm{~g}$ et la plus petite ouverture de tamis nécessitaient le plus d'énergie spécifique $(73,84 \mathrm{~J} / \mathrm{g})$. L'ouverture du tamis avait un effet sur la distribution de la longueur des fibres. Pour les trois scénarios de masse de l'alimentation, plus de fibres courtes étaient produites lorsqu'une ouverture de tamis plus petite était utilisée. Basé sur les résultats de l'analyse utilisant les lois existantes de Kick, Rittinger et Bond, un modèle linéaire a été développé pour décrire les données des essais en ce qui à trait à la relation entre l'énergie spécifique et les longueurs initiales et finales des fibres. Le modèle décrit bien les estimations énergétiques spécifiques particulièrement pour les cas où la masse d'alimentation est inférieure à 200 g. Mots clés: chanvre, décortication, fibre, énergie, broyeur à marteau.

\section{INTRODUCTION}

Hemp (Cannabis sativa L.) fibre has been used for different applications since early ages because of its outstanding mechanical and physical properties, such as high tensile strength and good thermal insulation character (Kozlowski 2000). Examples of applications include textile, pulp and paper manufacturing, biocomposites, automobile accessories, and thermal insulation materials (Fortenbery and Bennett 2004; Van Wyk 2007). Hemp fibre also has the potential to substitute carbon fibre and glass fibre in many other applications (Munder and Fürll 2004). Decortication is required in order to extract fibre from hemp stalk that basically consists of an outer layer of fibre and inner core. Decortication is a process that mechanically separates the outer fibre from the inner core. Various types of equipment have been used to decorticate hemp, including roll crushers (Hobson et al. 2000), modified forage harvesters (Gratton and Chen 2004), hammer mills (Munder and Fürll 2004), and ball mills (Baker et al. 2010). Among these types of decortication equipment, hammer mills and roll crushers are most commonly used for commercial fibre decortication. Hammer mills are more suitable for short fibre production that can be used in industrial composites or pulp manufacturing, while roll crushers are more suitable for long fibres production that are required for textile products. Compared to roll crushers, hammer mills require relatively low initial and maintenance cost, and they can process, with large capacity, hemp materials having various moisture and retting conditions. This study focused on the use of a hammer mill for decorticating retted hemp for short fibres.

Hammer mills have a long history of serving as size reduction machine in a wide range of applications such as biomass handling and flour grinding (Mani et al. 2003; Fang et al. 1998). Hammer mills were lately adapted for hemp decortication. When hammer mills are used for that purpose, hemp stalks are broken into shorter pieces (i.e. fibre and core are broken into pieces) by the force rendered from the rotating hammers. At the same time the impact forces separate fibre and core. 
Hammer mills have low energy efficiency (Lobo 2002). For this reason, many researchers have studied the energy requirements of hammer mills. Those studies focused on size reduction of different materials, and not on fibre decortication. Normally, specific energy is used to assess the energy consumption of hammer mills. Specific energy is defined as the energy consumed per unit feeding mass of material. Specific energy consumption of a hammer mill is related to the feedstock properties and to the hammer mill configuration. Vigneault et al. (1992) compared the specific energy, grinding rate, and particle size using a hammer mill with two hammer thickness scenarios: $3.2 \mathrm{~mm}$ and $6.4 \mathrm{~mm}$. The average specific energy for thin hammer tests was $10.2 \mathrm{~kW} \mathrm{~h} \mathrm{t}^{-1}$, which was $13.6 \%$ less than that of the thick hammer $\left(11.8 \mathrm{~kW} \mathrm{~h} \mathrm{t}^{-1}\right)$. The grinding rate was higher for the thin hammer configuration. Dziki and Laskowski (2005) investigated the relationship between wheat moisture, screen opening size, and the energy requirement based on experiments using a laboratory hammer mill. They found that more specific energy was required for higher moisture grain and smaller screen size led to higher specific energy requirement. Similar results in terms of screen opening size were also reported by Arthur et al. (1982) and Mani et al. (2004). Mani et al. (2004) compared the specific energy of grinding wheat and barley straw, corn stover, and switchgrass using a hammer mill. A negative correlation between the specific energy consumption and the screen opening size was found for each material at a moisture content of $8 \%$ (w.b.) or lower. Moisture content affected the specific energy at the same time; the higher the moisture content, the higher was the specific energy. Ghorbani et al. (2010) tested the specific energy of reducing the size of alfalfa chops on a hammer mill. The highest average specific energy of $30.51 \mathrm{~kJ} \mathrm{~kg}^{-1}$ was observed when the longest chops $(18 \mathrm{~mm})$ were ground using the smallest screen size of $1.68 \mathrm{~mm}$. Holtzapple et al. (1989) reported that a two-stage hammer mill required $0.18 \mathrm{MJ} \mathrm{kg}^{-1}$ electrical energy for reducing initial wood chip length of $25.4 \mathrm{~mm}$ into final length of $2.0 \mathrm{~mm}$. In summary, many factors affect specific energy of a hammer mill in size reduction applications, and the effects of feeding rate and screen opening sizes on the specific energy are critical. This study focused on these critical factors, but in a different application of hammer mills: hemp decortication, which has the purpose of separating fibre and core, involving the process size reduction as well.

The major energy input of hammer milling is consumed on size reduction of the feed, regardless of the application. Researchers have presented different size reduction laws relating the specific energy of size reduction to the initial and final sizes of the material. Among these theories, Kick's, Rittinger's, and Bond's size reduction laws are widely accepted (Lowrison 1974; Henderson and Perry 1976; Pfost and Swinehart 1970). Their theories are presented as the following equations:

$$
\begin{aligned}
& \mathrm{E}_{\mathrm{K}}=\mathrm{C}_{\mathrm{K}} \times \ln \left(\frac{\mathrm{L}_{1}}{\mathrm{~L}_{2}}\right) \\
& \mathrm{E}_{\mathrm{R}}=\mathrm{C}_{\mathrm{R}} \times\left(\frac{1}{\mathrm{~L}_{2}}-\frac{1}{\mathrm{~L}_{1}}\right) \\
& \mathrm{E}_{\mathrm{B}}=\mathrm{C}_{\mathrm{B}} \times\left(\frac{10}{\sqrt{\mathrm{L}_{2}}}-\frac{10}{\sqrt{\mathrm{L}_{1}}}\right)
\end{aligned}
$$

where $E_{K}, E_{R}$ and $E_{B}$ correspond to machine specific energy, as determined by means of Kick's, Rittinger's, and Bond's size reduction laws respectively; $C_{K}, C_{R}$, and $C_{B}$ are the corresponding constant factors; $\mathrm{L}_{1}$ and $\mathrm{L}_{2}$ are the initial size and the final size of the material respectively.

Equations 1 to 3 state that if the constant factors are known, specific energy requirement can be estimated based on the initial and final material sizes. The accuracy of the estimation depends on the type of the feed. For example, Ghorbani et al. (2010) used Kick's, Rittinger's, and Bond's laws according to the regression of the experimental data in size reduction of alfalfa by a hammer mill and they found that the Rittinger's law fitted the data best.

In summary, little research has been done on specific energy of hemp decortication. No literature was found in relating specific energy to hemp fibre lengths before and after decortication. The objectives of this study were to: 1) develop a general model for estimating specific energy required for hemp decortication through analyzing the Kick's, Rittinger's and Bond's size reduction laws; 2) measure energy requirement and fibre length distribution of hemp fibre decortication using a hammer mill; and 3) fit the general model with the measurements.

\section{MATERIALS AND METHODS}

\section{Experiment}

Decortication tests Data used in this study were collected from an experiment conducted by Baker (2010) on hemp fibre decortication using a hammer mill. Details on hemp samples, equipment (hammer mill) and experimental design have been described in Baker (2010). Here these are briefly summarized. The hemp samples (variety: USO 31) were from bales in a farm in western Manitoba (Canada). The hemp bales were retted in field for six weeks and then baled and stored outside. The moisture content of the hemp at the time of decortication was $9.7 \%$. Although moisture content of hemp would affect the energy requirement of decortication of the hemp, effects of moisture content were not within the scope of this study. The reason was that the moisture content suitable for safe storing bales varies only in a narrow range. Before being loaded into the hammer mill, the hemp feed was cut into segments using a heavyduty paper cut in order to prevent wrapping in the hammer mill. The hammer mill (Model E221.5 - TFA, Bliss Eliminator, Oklahoma, U.S.A) (Fig. 1a) had 24 swinging hammers symmetrically installed on the rotor (Fig. 1b). The scale of each hammer was $175 \times 50 \times 7 \mathrm{~mm}$. Hammer mill was installed with staggered perforated plate screens with round openings. A $22 \mathrm{~kW}$ motor drove the hammer rotor, rotating at a speed of $3600 \mathrm{rpm}$. 


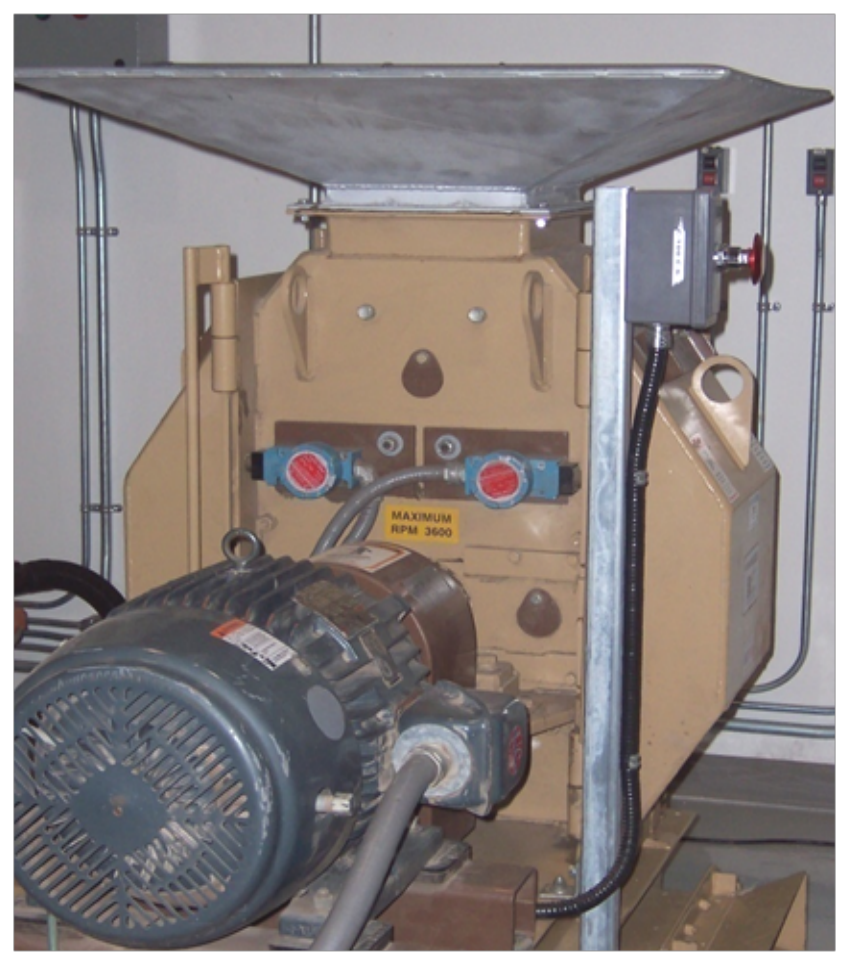

(a)

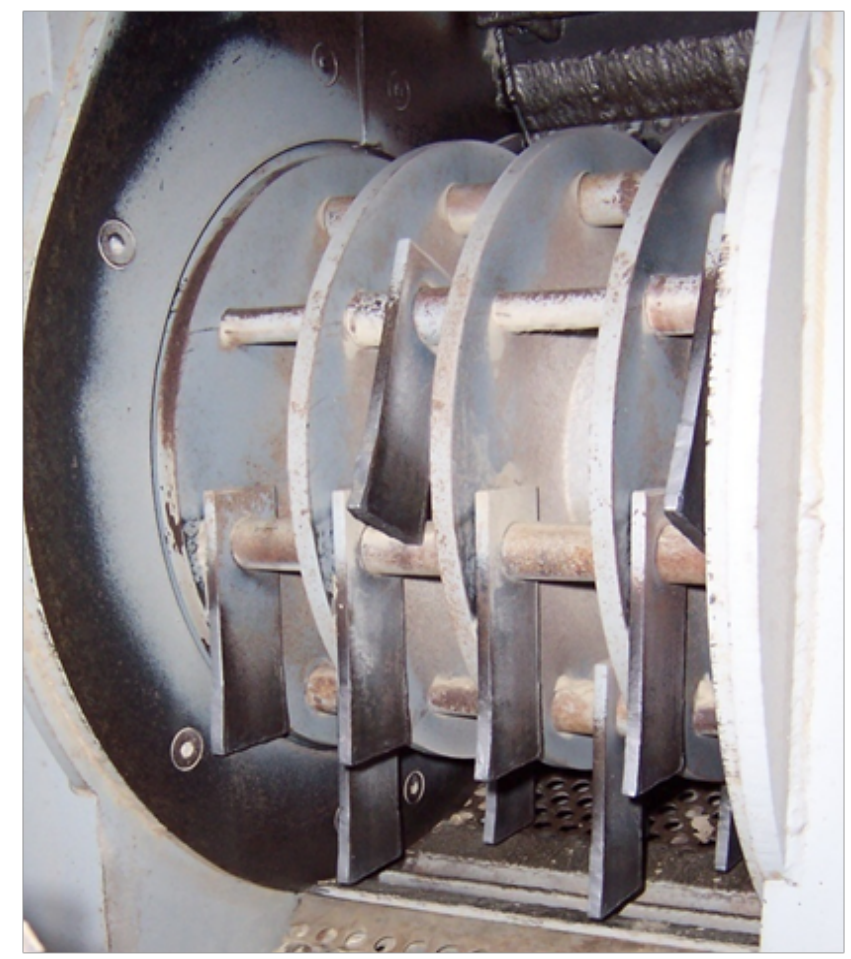

(b)

Fig. 1. Decortication equipment (Baker 2010): (a) hammer mill; (b) swing hammers.

The decortication experiment used three screen scenarios: $19.28 \mathrm{~mm}$ opening size (Fig. 2a), $25.74 \mathrm{~mm}$ opening size (Fig. 2b), and no screen; three feeding masses: $75 \mathrm{~g}, 125 \mathrm{~g}$, and $200 \mathrm{~g}$. Each experiment was conducted with four replications, which gave a total of 36 tests $(3$ screen scenarios $\times 3$ feeding masses $\times 4$ replications).

Energy measurement The power of the hammer mill motor was measured through measuring the motor torque and speed using a sensor kit, a laptop computer, and the 9000XDrive Software. The power data were recorded every 0.1 second during decortication. In a decortication

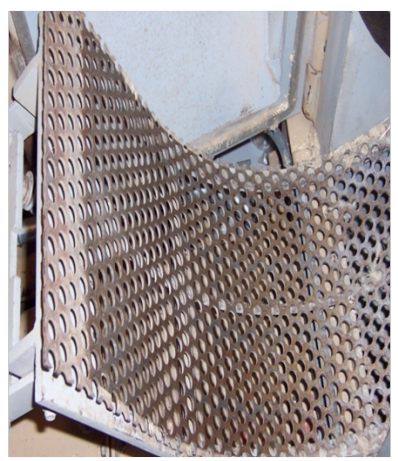

(a)

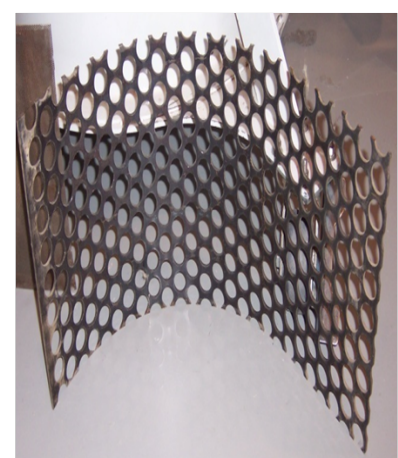

(b)
Fig. 2. Staggered perforated screen of the hammer mill (Baker 2010): (a) opening size $19.28 \mathrm{~mm}$; (b) opening size $25.74 \mathrm{~mm}$. test, the hammer mill was first turned on at the no-load status. Once the hammers reached a constant rotational speed, hemp feed with the desired mass was manually fed into the hopper over the hammers. Figure 3 shows a typical power-time curve recorded. The bell shape of the curve was due to the batch-fed mode. The horizontal line before the curve represented the no-load power of the motor shaft, which was $594 \mathrm{~W}$ averaged over all tests. The ascent of the curve was because of the increasing power required during decortication of the fed hemp. The power value decreased as the decortication process was gradually completed.

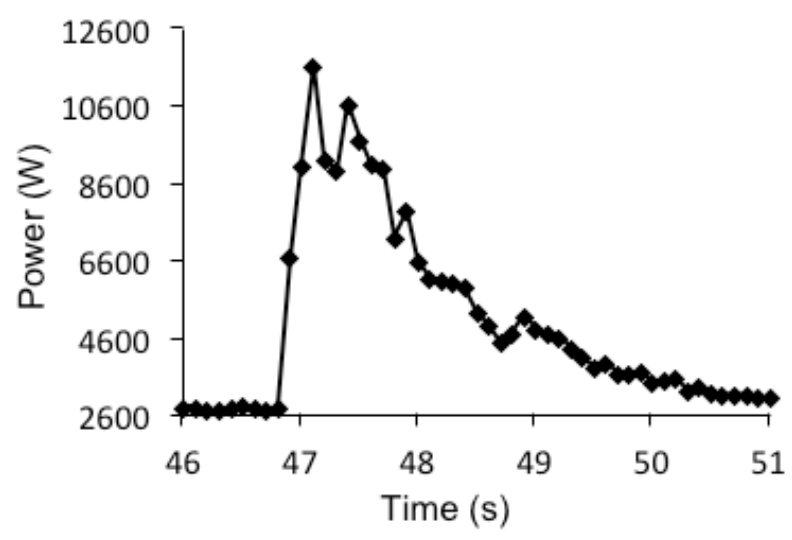

Fig. 3. Typical power-time curve; data from the treatment: $25.74 \mathrm{~mm}$ screen with $200 \mathrm{~g}$ feeding mass. 
To determine the net power required for decorticating hemp, the no-load power was deducted from the total power; then the net energy for decorticating hemp was determined by integrating the area under the net power vs. time curve using the following equation:

$$
\mathrm{E}_{\mathrm{net}}=\left(\frac{\mathrm{y}_{2}+\mathrm{y}_{1}}{2}\right) \times \Delta \mathrm{t}+\left(\frac{\mathrm{y}_{3}+\mathrm{y}_{2}}{2}\right) \times \Delta \mathrm{t}+\cdots+\left(\frac{\mathrm{y}_{\mathrm{n}}+\mathrm{y}_{\mathrm{n}-1}}{2}\right) \times \Delta \mathrm{t}
$$

where: $E_{\text {net }}=$ net energy $(J) ; y_{1}=$ the net power value of the first data point $(\mathrm{W}) ; \mathrm{y}_{2}=$ the net power value of the second data point $(\mathrm{W}) ; \mathrm{y}_{\mathrm{n}}=$ the net power value of the $\mathrm{n}^{\text {th }}$ data point (W); and $\Delta \mathrm{t}=$ time interval (s).

Dividing total net energy by the feeding mass, the specific net energy can be obtained as follows (Eq. 5).

$$
\mathrm{E}=\frac{\mathrm{E}_{\mathrm{net}}}{\mathrm{M}}
$$

where: $\mathrm{E}=$ specific net energy $(\mathrm{J} / \mathrm{g})$; and $\mathrm{M}=$ feeding mass (g).
Fibre length analysis After each decortication test, the output (mixture of fibres and cores) of the hammer mill was collected, and the fibres were manually separated from the output. Short fibres were separated carefully from the mixture by tweezers. Lengths of the fibres were manually measured with rulers. The length distribution of the fibres was characterized with six length categories: 0$20 \mathrm{~mm}, 20-40 \mathrm{~mm}, 40-60 \mathrm{~mm}, 60-80 \mathrm{~mm}, 80-100 \mathrm{~mm}$, and longer than $100 \mathrm{~mm}$. Fibres in each category were weighed by a digital scale and the proportion value of each category was recorded. The initial fibre length, i.e. fibre length before decorticating, was also measured; in the measurements, ten fibres from the initial hemp sample were randomly chosen and measured to obtain the average initial length. These measurements were used for the model development described later in the paper.

\section{Model development}

Analysis of existing size reduction laws Kick's, Rittinger's, and Bond's (Eqs. 1,2,3) size reduction laws are for estimating energy required for size reduction of a
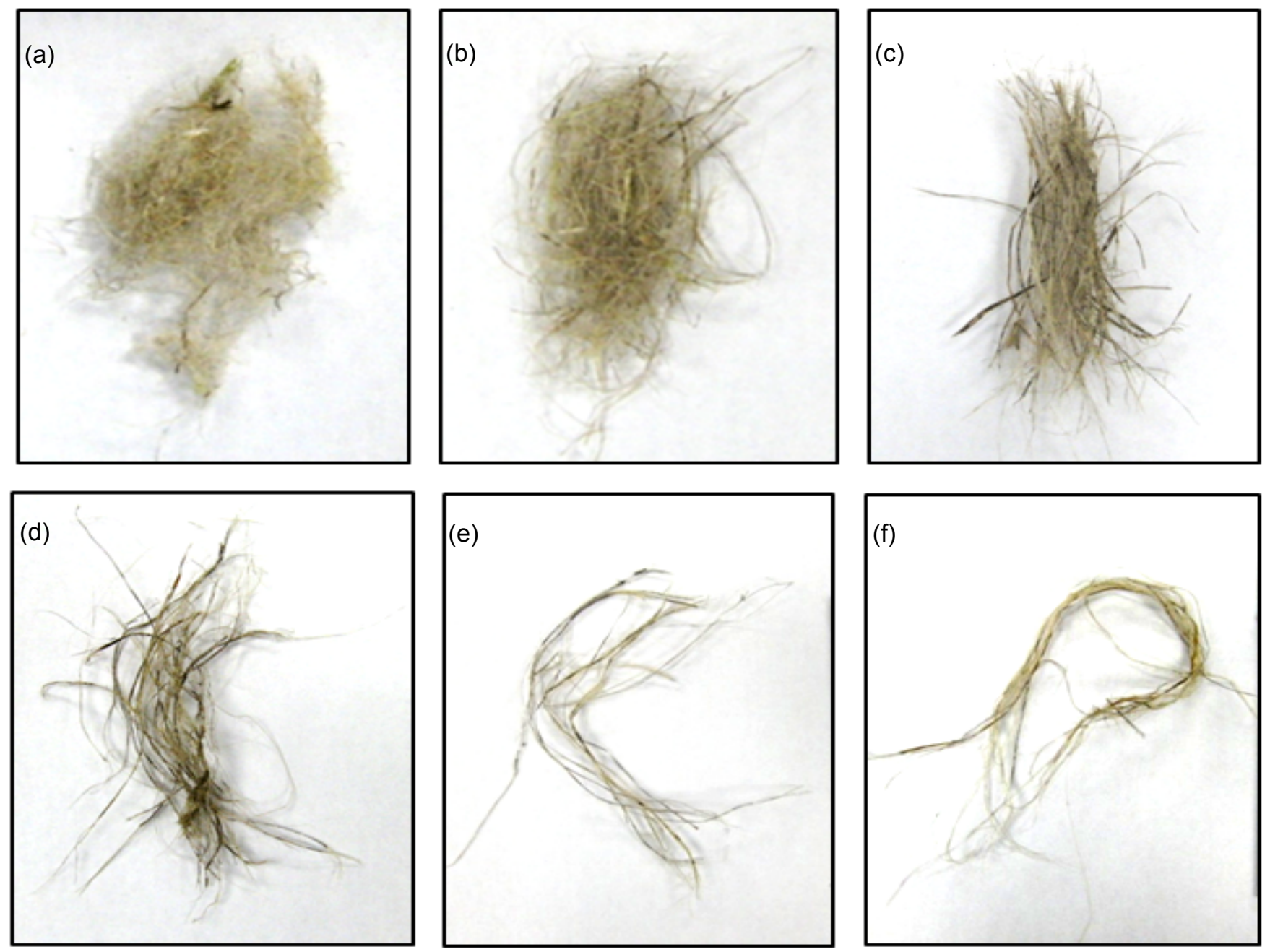

Fig. 4. Output fibres in different length categories: (a) 0-20 mm; (b) 20-40 mm; (c) 40-60 mm; (d) 60-80 mm;(e) 80-100 mm; (f) $>100 \mathrm{~mm}$. 
material consisting of a single component. However, the output hemp material from the hammer mill consisted of two components: fibres and cores. The specific net energy can be simplified in two parts: specific energy of fibre and specific energy of core as follows:

$$
\mathrm{E}=\mu_{\mathrm{c}} \mathrm{E}_{\mathrm{c}}+\mu_{\mathrm{f}} \mathrm{E}_{\mathrm{f}}
$$

where: $\mu_{\mathrm{c}}=$ mass proportion of core fraction; $\mu_{\mathrm{f}}=$ mass proportion of fibre fraction; $\mathrm{E}_{\mathrm{c}}=$ Specific net energy of core $(\mathrm{J} / \mathrm{g})$; and $\mathrm{E}_{\mathrm{f}}=$ Specific net energy of fibre $(\mathrm{J} / \mathrm{g})$. It was assumed that each part follows the existing size reduction law. Based on this, the existing size reduction laws were modified. To describe the procedure of the analysis for different size reduction laws, nomenclature parameters are labelled with subscripts $\mathrm{K}, \mathrm{R}$, and $\mathrm{B}$, representing for Kick, Rittinger, and Bond respectively. The modification is explained here using the Kick's law as an example. Taking fibre and core separately, the original Kick's law (Eq. 1) is expressed as:

$$
\begin{aligned}
& E_{c}=C_{K c} \times \ln \frac{L_{1 c}}{L_{2 c}} \\
& E_{f}=C_{K f} \times \ln \frac{L_{1 f}}{L_{2 f}}
\end{aligned}
$$

where: $\mathrm{C}_{\mathrm{Kc}}=$ constant factor for core; $\mathrm{C}_{\mathrm{Kf}}=$ constant factor for fibre; $\mathrm{L}_{1 \mathrm{c}}=$ initial core length $(\mathrm{mm}) ; \mathrm{L}_{1 \mathrm{f}}=$ initial fibre length $(\mathrm{mm}) ; \mathrm{L}_{2 \mathrm{c}}=$ final core length $(\mathrm{mm})$; and $\mathrm{L}_{2 \mathrm{f}}=$ final fibre length $(\mathrm{mm})$.

In practice, most cores are rejected (commonly by air flow) to a waste stream during decortication process and thus their length distribution cannot be easily quantified. This made applications of these existing size reduction laws complicated. A theoretical analysis was first performed to simply relate the specific energy with the initial and final lengths of fibres only, i.e. without using the information on sizes of cores. This can be justified by the following facts: the fairly uniform initial lengths of fibre and core were controlled by the pre-cutting procedure; the proportions of fibre content of hemp vary in a very narrow range (25-35\%) (BCMAF 1999). It is assumed that the ratio of final core and fibre lengths was constant due to some inherent character of hemp. The ratio of final core and fibre lengths should be mechanicalproperty dependent, thus it is reasonable to consider it as constant under the same decortication condition. Sadek et al. (2011) reported the shear properties of hemp fibre and core using the discrete element modeling method. Their results indicated a relatively constant ratio between fibre and core shear stresses, which to some extent strengthened the hypothesis. Based on these facts, the following assumptions were made:

- the initial length of the core $\mathrm{L}_{1 \mathrm{c}}$ equals the initial length of the fibre $\mathrm{L}_{1 \mathrm{f}}$;

- the relationship between final length of the core and fibre is $L_{2 c}=r L_{2 f}$, where $r$ is a constant;

- the proportion of core $\mu_{\mathrm{c}}$ and the proportion of fibre $\mu_{\mathrm{f}}$ within hemp stalk are constants.
Substituting $\mathrm{L}_{1 \mathrm{c}}$ and $\mathrm{L}_{2 c}$ by the terms of $\mathrm{L}_{1 \mathrm{f}}$ and $\mathrm{L}_{2 \mathrm{f}}$ in Eqs. 7 and 8 and combining with Eq. 6, the following equations are obtained:

$$
\begin{aligned}
& E_{K}=\mu_{c} \cdot C_{K c} \cdot \ln \frac{L_{1 f}}{r \cdot L_{2 f}}+\mu_{f} \cdot C_{K f} \cdot \ln \frac{L_{1 f}}{L_{2 f}} \\
& E_{K}=\left(\mu_{c} \cdot C_{K c}+\mu_{f} \cdot C_{K f}\right) \ln \frac{L_{1 f}}{L_{2 f}}+\mu_{c} \cdot C_{K c} \cdot \ln \frac{1}{r}
\end{aligned}
$$

The final length of the fibre generated by a hammer mill greatly varies. For instance, in this study, the final fibre length varied from shorter than $20 \mathrm{~mm}$ to longer than $100 \mathrm{~mm}$. The details in fibre length distribution are discussed later in the paper. To consider the length variation of the final fibre, $\mathrm{E}_{\mathrm{K}}$ could be calculated as:

$$
\begin{gathered}
\mathrm{E}_{\mathrm{K}}=\left(\mu_{\mathrm{c}} \cdot \mathrm{C}_{\mathrm{Kc}}+\mu_{\mathrm{f}} \cdot \mathrm{C}_{\mathrm{Kf}}\right) \times \ln \left(\sum_{\mathrm{i}=1}^{\mathrm{n}} \delta_{\mathrm{i}} \frac{\mathrm{L}_{1 \mathrm{f}}}{\mathrm{L}_{2 \mathrm{fi}}}\right) \\
+\mu_{\mathrm{c}} \cdot \mathrm{C}_{\mathrm{Kc}} \cdot \ln \frac{1}{\mathrm{r}}
\end{gathered}
$$

where: $\delta_{\mathrm{i}}=$ the mass proportion of the $\mathrm{i}^{\text {th }}$ length category; $\mathrm{n}=$ the number of length categories; and $\mathrm{L}_{2 \mathrm{fi}}=$ average output fibre length of the $\mathrm{i}^{\text {th }}$ length category $(\mathrm{mm})$.

The Eq. 10 can be rewritten in the following general form:

$$
\mathrm{E}_{\mathrm{K}}=\mathrm{C}_{\mathrm{K}} \cdot \mathrm{X}_{\mathrm{K}}+\mathrm{b}_{\mathrm{K}}
$$

where: $C_{K}=a$ constant factor; and $b_{K}=$ a constant term according to the assumptions (J/g). $\mathrm{X}_{\mathrm{K}}$ represents $\ln \left(\sum_{\mathrm{i}=1}^{\mathrm{n}} \delta_{\mathrm{i}} \frac{\mathrm{L}_{1 \mathrm{f}}}{\mathrm{L}_{2 \mathrm{fi}}}\right)$, and it is the independent variable in Eq. 11. Equation 11 is a modified Kick's law which relates the total specific net energy with the initial and final length of the fibre fraction only.

By following the same process as described above, the Rittinger's and Bond's laws were also modified and they are as follows:

$$
\begin{gathered}
E_{R}=\left(\frac{\mu_{c} \cdot C_{R c}}{r}+\mu_{f} \cdot C_{R f}\right) \cdot \sum_{i=1}^{n} \delta_{i}\left(\frac{1}{L_{2 f i}}-\frac{1}{L_{1 f}}\right) \\
+\left(\frac{\mu_{c} \cdot C_{R c}}{L_{1 f} \cdot r}-\frac{\mu_{c} \cdot C_{R c}}{L_{1 f}}\right) \\
E_{R}=C_{R} \cdot X_{R}+b_{R} \\
E_{B}=\left(\frac{\mu_{c} \cdot C_{B c}}{\sqrt{r}}+\mu_{f} \cdot C_{B f}\right) \cdot \sum_{i=1}^{n} \delta_{i}\left(\frac{10}{\sqrt{L_{2 f i}}}-\frac{10}{\sqrt{L_{1 f}}}\right) \\
\quad+\left(\frac{10 \cdot \mu_{c} \cdot C_{B c}}{\sqrt{L_{1 f}} \cdot \sqrt{r}}-\frac{10 \cdot \mu_{c} \cdot C_{B c}}{\sqrt{L_{1 f}}}\right)
\end{gathered}
$$

Variables $b_{R}$ and $b_{B}(J / g)$ were coefficients related to the initial fibre length that was considered as unchanged in this study. The expressions of $\mathrm{C}, \mathrm{X}$, and $\mathrm{b}$ for the three modified laws are summarized in Table 1.

Energy model for hemp decortication According to the above analysis, all modified Kick's, Rittinger's, and Bond's models have the following general format: 


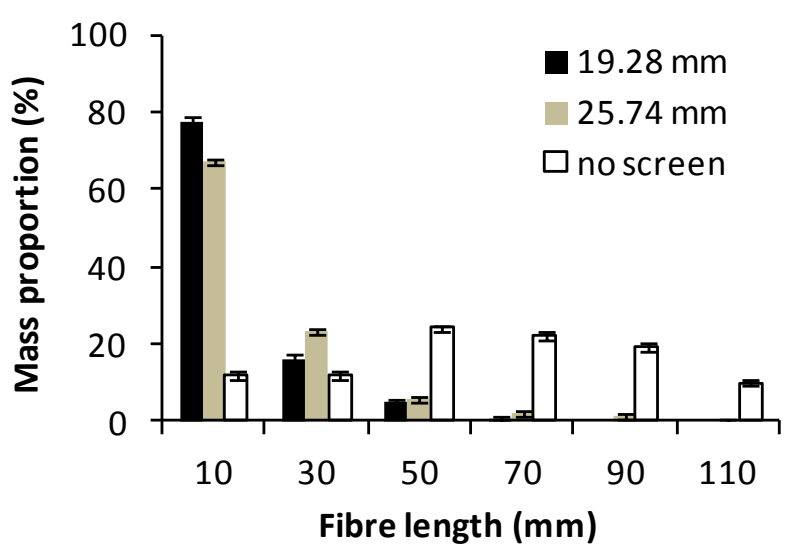

(a)

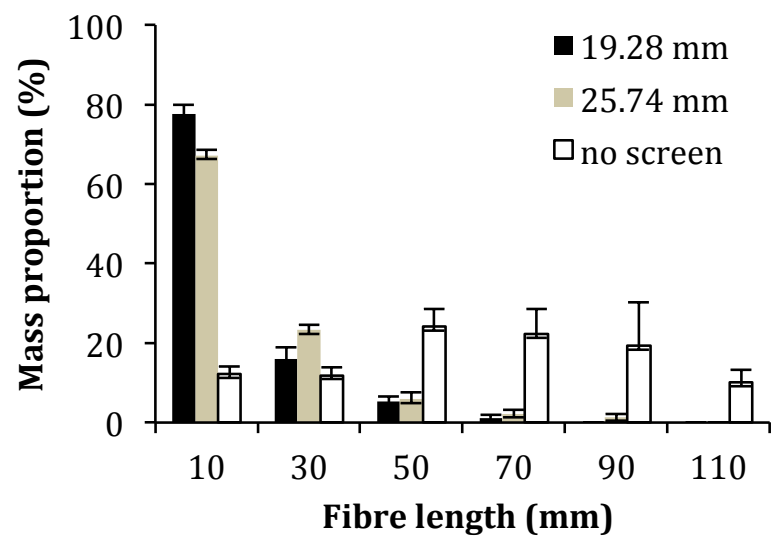

(b)

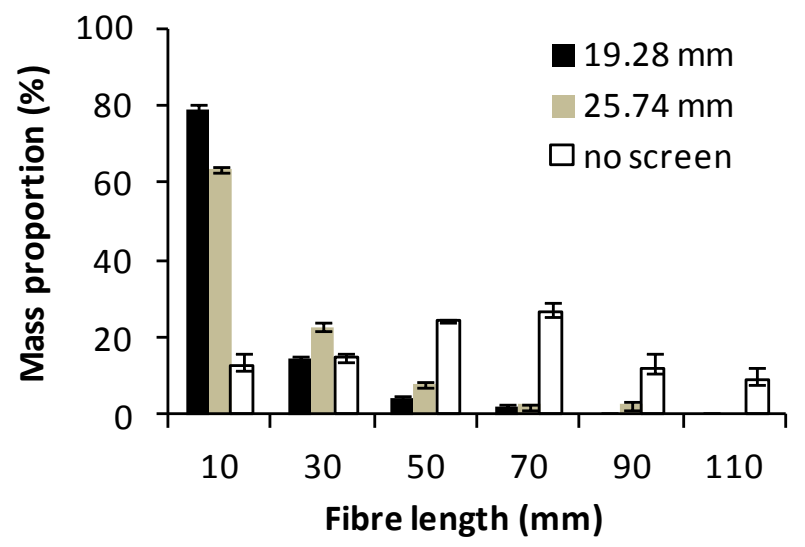

(c)

Fig. 5. Length distribution of different feeding masses: (a) $200 \mathrm{~g}$; (b) $125 \mathrm{~g}$; (c) $75 \mathrm{~g}$.

$\mathrm{E}=\mathrm{CX}+\mathrm{b}$

The slope of the regression equations $\mathrm{C}(\mathrm{J} / \mathrm{g})$ represents the constant factors: $C_{K}, C_{R}$ or $C_{B}$ and the intersection represents the constant factors: $b_{K}, b_{R}$ or $b_{B}$ in the modified relationships. Although $\mathrm{X}$ is not a single variable (but a function of initial and final fibre lengths), Eq. 16 can be treated as a "linear model", and this form of linear model is considered to represent specific energy requirement in hemp decortication. For the decortication energy model, the parameter $\mathrm{X}$ is considered simply as the ratio of initial and final fibre length:

$$
X=\frac{L_{1 f}}{\overline{L_{2 f}}}
$$

where: $\overline{\mathrm{L}_{2 \mathrm{f}}}=$ the average final fibre length $(\mathrm{mm})$. The average final fibre length $\overline{\mathrm{L}_{2 \mathrm{f}}}$ was calculated by the following equation:

$$
\overline{\mathrm{L}_{2 \mathrm{f}}}=\sum_{\mathrm{i}=1}^{\mathrm{n}} \delta_{\mathrm{i}} \cdot \mathrm{L}_{2 \mathrm{fi}}
$$

The decortication energy model has the format as follows:

$$
\mathrm{E}=C \frac{\mathrm{L}_{1 \mathrm{f}}}{\overline{\overline{\mathrm{L}_{2 \mathrm{f}}}}}+b
$$

The advantage of the linear model is that it is very simple, and no core length distribution but only fibre distribution is analyzed. The constant factors $\mathrm{C}$ and $\mathrm{b}$ were obtained from linear regression based on the experimental data of specific energy and length distribution, as discussed in the following section.

\section{RESULTS AND DISCUSSION}

\section{Measured fibre length}

The average initial fibre length before decortication was $111 \mathrm{~mm}$. Fibres after decortication were separated manually into different length categories (Fig. 4). Results of length distribution (average length and standard deviation) for each screen scenario under different feeding masses are presented in Fig. 5. For the screen opening size of $19.28 \mathrm{~mm}$ and $25.74 \mathrm{~mm}$, majority fraction of the output was short fibres in the range of $0-20 \mathrm{~mm}$. With the screen size of $19.28 \mathrm{~mm}$, all fibres were shorter than 80 $\mathrm{mm}$, while product from the $25.74 \mathrm{~mm}$ screen scenario contained only small proportion (less than $3 \%$ ) of fibres longer than $80 \mathrm{~mm}$. The no-screen scenario produced fibres spreading in all length categories, and approximately half of the fibres were within $40-80 \mathrm{~mm}$. With screens $(19.28$ and $25.74 \mathrm{~mm})$, the decortication process produced more short fibres comparing with the no screen scenario. This result agreed with conclusions from other studies that smaller screen opening size provided finer products (Ghorbani et al. 2010; Mani et al. 2003). Feeding mass in the range from $75 \mathrm{~g}$ to $200 \mathrm{~g}$ did not show obvious effect on the final fibre length.

\section{Measured specific energy}

The highest net energy and the highest specific energy was $14.77 \mathrm{~kJ}$ and $73.84 \mathrm{~J} / \mathrm{g}$ respectively when the small opening size $(19.28 \mathrm{~mm})$ screen was used to decorticate $200 \mathrm{~g}$ feeding hemp sample (Table 2). The no screen scenario with $75 \mathrm{~g}$ feeding mass required both lowest average net energy $(0.70 \mathrm{~kJ})$ and lowest average specific energy $(9.31 \mathrm{~J} / \mathrm{g})$. The trends of specific energy were that higher feeding mass resulted in higher specific energy and smaller screen opening resulted in higher specific energy to complete decortication. Similar trends were observed for net energy. This result agrees with the conclusions of some studies using hammer mill in size reduction of crops, grains, and residues (Mani et al. 2004; Ghorbani et al. 2010; Arthur et al. 1982; Dziki and Laskowski 2005). 
Table 1. Summary of $C, X$, and b expressions in three modified laws.

\begin{tabular}{|c|c|c|c|}
\hline Modified law & $\mathrm{C}_{(\mathrm{K}, \mathrm{R} \text { or } \mathrm{B})}$ & $\mathrm{X}_{(\mathrm{K}, \mathrm{R} \text { or } \mathrm{B})}$ & $\overline{b_{(K, R \text { or } \mathrm{B})}}$ \\
\hline Kick's & $\mu_{\mathrm{c}} \cdot \mathrm{C}_{\mathrm{Kc}}+\mu_{\mathrm{f}} \cdot \mathrm{C}_{\mathrm{Kf}}$ & $\ln \left(\sum_{\mathrm{i}=1}^{\mathrm{n}} \delta_{\mathrm{i}} \frac{\mathrm{L}_{1 \mathrm{f}}}{\mathrm{L}_{2 \mathrm{fi}}}\right)$ & $\mu_{\mathrm{c}} \cdot \mathrm{C}_{\mathrm{Kc}} \cdot \ln \frac{1}{\mathrm{r}}$ \\
\hline Rittinger's & $\frac{\mu_{c} \cdot C_{R c}}{r}+\mu_{f} \cdot C_{R f}$ & $\sum_{\mathrm{i}=1}^{\mathrm{n}} \delta_{\mathrm{i}}\left(\frac{1}{\mathrm{~L}_{2 \mathrm{fi}}}-\frac{1}{\mathrm{~L}_{1 \mathrm{f}}}\right)$ & $\frac{\mu_{c} \cdot C_{R c}}{L_{1 f} \cdot r}-\frac{\mu_{c} \cdot C_{R c}}{L_{1 f}}$ \\
\hline Bond's & $\frac{\mu_{\mathrm{c}} \cdot \mathrm{C}_{\mathrm{Bc}}}{\sqrt{\mathrm{r}}}+\mu_{\mathrm{f}} \cdot \mathrm{C}_{\mathrm{Bf}}$ & $\sum_{\mathrm{i}=1}^{\mathrm{n}} \delta_{\mathrm{i}}\left(\frac{10}{\sqrt{\mathrm{L}_{2 \mathrm{fi}}}}-\frac{10}{\sqrt{\mathrm{L}_{1 \mathrm{f}}}}\right)$ & $\frac{10 \cdot \mu_{\mathrm{c}} \cdot \mathrm{C}_{\mathrm{Bc}}}{\sqrt{\mathrm{L}_{1 \mathrm{f}}} \cdot \sqrt{\mathrm{r}}}-\frac{10 \cdot \mu_{\mathrm{c}} \cdot \mathrm{C}_{\mathrm{Bc}}}{\sqrt{\mathrm{L}_{1 \mathrm{f}}}}$ \\
\hline
\end{tabular}

The standard errors of average specific energy for 75 $\mathrm{g}$ feeding mass cases were relatively high. The reason might be that machine energy output was not stable when processing smaller amount of feeding mass, and it would cause fluctuations in motor torque and data transmitted to the recording facility. With higher feeding mass, the recorded energy data approached to a relatively stable status for each replication.

Fitting the decortication energy model using the data Regression analysis was performed using the experimental data. The term $\frac{\mathrm{L}_{1 f}}{\overline{\mathrm{L}_{2 f}}}$ was determined first and it was used as independent variable in the linear regression. Regression was done for each feeding mass and the combined mass. The resultant regression coefficients are summarized in Table 3. For example, the relationship between decortication specific energy $\mathrm{E}(\mathrm{J} / \mathrm{g})$ and the ratio of initial and average final fibre length for the combined data was expressed by the equation below:

$$
\mathrm{E}=9.11 \times \frac{\mathrm{L}_{1 \mathrm{f}}}{\overline{\mathrm{L}_{2 \mathrm{f}}}}-2.43
$$

where $\mathrm{L}_{1 \mathrm{f}}$ and $\overline{\mathrm{L}_{2 f}}$ are in $\mathrm{mm}$, and $\mathrm{E}$ is in $\mathrm{J} / \mathrm{g}$.

Among three different feeding masses, the greatest slope was found for the $200 \mathrm{~g}$ feeding mass. However,

\section{Table 2. Specific energy of decortication.}

\begin{tabular}{ccccc}
\hline $\begin{array}{c}\text { Screen } \\
\text { scenario }\end{array}$ & $\begin{array}{c}\text { Feeding } \\
\text { mass }\end{array}$ & $\begin{array}{c}\text { Average } \\
\text { net energy }\end{array}$ & $\begin{array}{c}\text { Average } \\
\text { specific } \\
\text { energy } E_{S} \\
(\mathrm{~mm})\end{array}$ & $\begin{array}{c}\text { Standard } \\
\text { errors }\end{array}$ \\
\hline 19.28 & 200 & 14.77 & 73.84 & \pm 5.80 \\
& 125 & 7.13 & 57.02 & \pm 10.29 \\
& 75 & 3.97 & 52.90 & \pm 15.52 \\
25.74 & 200 & 11.56 & 57.78 & \pm 3.31 \\
& 125 & 5.62 & 44.95 & \pm 9.08 \\
& 75 & 3.01 & 40.06 & \pm 10.73 \\
no screen & 200 & 3.03 & 15.17 & \pm 1.63 \\
& 125 & 2.38 & 19.00 & \pm 3.51 \\
& 75 & 0.70 & 9.31 & \pm 4.19 \\
\hline
\end{tabular}

there were no particular trends for the effects of feed mass on the regression coefficients. The model described reasonably well the relationship of specific energy and fibre length, as indicated by the coefficient of determination $\left(\mathrm{R}^{2}\right)$ from 0.74 to 0.96 . The highest $\mathrm{R}^{2}$ was found for the model of the $200 \mathrm{~g}$ feeding mass. Note that the models in Table 3 are applicable only in the given ranges of independent variable $X$, and the $X$ is not a single variable, but the ratio of initial and average final fibre length.

\section{CONCLUSIONS}

Length distribution of the output fibres from decortication using a hammer mill with screen scenarios of $19.28 \mathrm{~mm}$ and $25.74 \mathrm{~mm}$ opening indicated that majority of fibres were shorter than $20 \mathrm{~mm}$. Small screen opening size produced more fine fibres than larger sized screen and noscreen cases. Feeding mass had little effect on length distribution. The highest specific energy $(73.84 \mathrm{~J} / \mathrm{g})$ was required when using small opening size screen $(19.28 \mathrm{~mm})$ to process $200 \mathrm{~g}$ retted hemp. The analysis of Kick's, Rittinger's, and Bond's laws showed that specific energy requirement of decorticated hemp material which consists of both fibre and core can be determined using different length fractions of hemp fibre only. The three existing laws could be envisioned as a general linear model. The linear model was fitted with measurements of specific energy and fibre length distribution. The resultant models described

\section{Table 3. Summary of $C$ and $b$ values of the} decortication energy model.

\begin{tabular}{ccccc}
$\begin{array}{c}\text { Feeding mass } \\
(\mathrm{g})\end{array}$ & $\begin{array}{c}\mathrm{C} \\
(\mathrm{J} / \mathrm{g})\end{array}$ & $\begin{array}{c}\mathrm{b} \\
(\mathrm{J} / \mathrm{g})\end{array}$ & $\begin{array}{c}\mathrm{R}^{2} \\
\text { value }\end{array}$ & Range of $\mathrm{X}$ \\
\hline Combined data & 9.11 & -2.43 & 0.76 & $1.64 \leq \mathrm{X} \leq 7.54$ \\
200 & 11.13 & -4.39 & 0.96 & $1.87 \leq \mathrm{X} \leq 7.54$ \\
125 & 7.04 & 6.21 & 0.74 & $1.64 \leq \mathrm{X} \leq 7.25$ \\
75 & 9.02 & -8.29 & 0.76 & $1.81 \leq \mathrm{X} \leq 7.12$ \\
\hline
\end{tabular}


the hemp decortication data using a hammer mill with the $\mathrm{R}^{2}$ value as high as 0.97 in the case of $200 \mathrm{~g}$ feeding mass. Lower $\mathrm{R}^{2}$ values (0.74-0.76) were observed for the two lower feeding masses and the combined feed mass.

This study provides preliminary information on how fibre length changes before and after decortication affect the specific energy requirement of a hammer mill. The modified laws were analysed and linear models were developed based on certain assumptions and data from a given hammer mill and a given hemp feedstock. These may affect the accuracy of the models in energy prediction. Caution should be taken when using the results.

\section{ACKNOWLEDGEMENT}

The study was funded by Natural Sciences and Engineering Research Council of Canada (NSERC). Thanks are also given to Composites Innovation Centre Manitoba Inc., Emerson Hemp Distribution Company, and Parkland Industrial Hemp Growers Co-op Ltd for their support to the project.

\section{REFERENCES}

Arthur, J.F., R.A. Kepner, J.B. Dobie, G.E. Miller and P.S. Parsons. 1982. Tub grinder performance with crop and forest residues. Transactions of the ASAE 25(6): 1488-1494.

Baker, M., Y. Chen, C. Laguë, H. Landry, Q. Peng and W. Zhong. 2010. Hemp fibre decortication using a planetary ball mill. Canadian Biosystems Engineering 52 (2010): 2.7-2.15.

Baker, M. 2010. Evaluation of a hammer mill and planetary ball mill for hemp fibre decortication. Unpublished M.Sc. thesis. Winnipeg MB: Department of Biosystems Engineering, University of Manitoba.

BCMAF. 1999. Industrial Hemp (Cannabis sativa L.) Special crop factsheet, Ministry of Agriculture and Food BC. http://www.agf.gov.bc.ca/speccrop/publications/docu ments/hempinfo.pdf (2012/10/04).

Dziki, D. and J. Laskowski. 2005. Influence of selected factors on wheat grinding energy requirements. TEKA Commission of Motorization and Power Industry in Agriculture 5: 56-64.

Fang, Q., E. Haque, C.K. Spillman, P.V. Reddy and J.L. Steele. 1998. Energy requirements for size reduction of wheat using a roller mill. Transactions of the ASAE 41(6): 1713-1720.

Fortenbery, T.R. and M. Bennett. 2004. Opportunities for commercial hemp production. Review of Agricultural Economics 26: 97-117.

Ghorbani, Z., A.A. Masoumi and A. Hemmat. 2010. Specific energy consumption for reducing the size of alfalfa chops using a hammer mill. Biosystems Engineering 105(1): 34-40.
Gratton, J.L. and Y. Chen. 2004. Development of a fieldgoing unit to separate fibre from hemp. Applied Engineering in Agriculture 20(2): 139-145.

Henderson, S.M. and R.L. Perry. 1976. Agricultural Process Engineering, 3rd edition. Westport, CT. AVI Publishing Company Inc.

Hobson, R.N., D.G. Hepworth and D.M. Bruce. 2000. Quality of fibre separated from unretted hemp stems by decortication. Journal of Agricultural Engineering and Research 78(2): 153-158.

Holtzapple, M.T., A.E. Humphrey and J.D. Taylor. 1989. Energy requirements for the size reduction of poplar and aspen wood. Biotechnology and Bioengineering 33: $207-210$.

Kozlowski, R. 2000. Potential and diversified uses of green fibres. In Third International Wood and Nature Fibres Composites Symposium, 1-14. Kassel, Germany. September 19-20.

Lobo, P. 2002. The right grinding solution for you: roll, horizontal or vertical. Feed Management 53(3): 2326.

Lowrison, G.C. 1974. Crushing and Grinding: The Size Reduction of Solid Materials. London, UK: Butterworths.

Mani, S., L.G. Tabil, S. Sokhansanj and M. Roberge. 2003. Mechanical properties of corn stover grind. ASAE Meeting Paper No. 036090. St. Joseph, MI: ASAE.

Mani, S., L.G. Tabil and S. Sokhansanj. 2004. Grinding performance and physical properties of wheat and barley straws, corn stover and switchgrass. Biomass and Bioenergy 27: 339-352.

Munder, F. and C. Fürll. 2004. Effective processing of bast fiber plants and mechanical properties of the fibers. ASAE/CSAE Meeting Paper No. 046091. St. Joseph, MI: ASAE.

Pfost, H.B. and C.E. Swinehart. 1970. Feed Manufacturing Technology. Chicago, IL: American Feed Manufacturers Association Inc.

Sadek, M.A., Y. Chen, C. Laguë, H. Landry, Q. Peng and W. Zhong. 2011. Characterization of the shear properties of hemp fiber and core using the discrete element method. Transactions of the ASABE 54(6): 2279-2285.

Van Wyk, L. 2007. The application of natural fibre composites in construction: a case study. In Sixth International Conference on Composite Science and Technology, 1-14. Durban, South Africa. January 2224.

Vigneault, C., T.M. Rothwell and G.B. Bourgeois. 1992. Hammermill grinding rate and energy requirements for thin and conventional hammers. Canadian Agricultural Engineering 34(2): 203-207. 